Running heads: Chinese Gift-giving Behavior H. Feng et al. Asian Journal of Communication

\title{
Article Title:
}

\section{Examining Chinese Gift-giving Behavior from the Politeness Theory Perspective}

\author{
Hairong Feng, Hui-Ching Chang, Richard Holt \\ ${ }^{a}$ Department of Communication, University of Minnesota Duluth, Duluth, the United States; \\ ${ }^{b}$ Department of Communication, University of Illinois Chicago, Chicago, the United States; \\ ${ }^{c}$ Department of Communication, Northern Illinois University, Dekalb, the United States
}

Full correspondence details:

Hairong Feng ( $\mathrm{PhD}$, Purdue University) is an assistant professor at the University of Minnesota Duluth. Hui-Ching Chang (PhD, University of Illinois Urbana-Champaign) is an associate professor at University of Illinois Chicago. Richard Holt $(\mathrm{PhD}$, University of Illinois Urbana-Champaign) is a professor at Northern Illinois University. Correspondence to Hairong Feng, University of Minnesota Duluth, 465 A. B. Anderson Hall, 1121 University Drive, Duluth, MN 55812, USA; E-mail: hfeng@d.umn.edu.

(Received 21 December 2009; final version received December 2010)

\begin{abstract}
This study examines how power, social distance, and ranking of imposition specified in Brown and Levinson's politeness theory influence positive and negative politeness strategies used in Chinese gift-giving. We utilize a 2 × 2 × 2 repeated measure within subject design. Responses from 152 Chinese were subjected to analyses of repeated measure ANOVAs. Results revealed significant main effects and interaction effects for power, social distance, and ranking of imposition on politeness strategies in Chinese gift-giving behaviors. Theoretical and practical implications of the results and future research directions are discussed.
\end{abstract}

Keywords: politeness theory, politeness strategies, Chinese gift-giving, culture

The ritual of gift-giving occurs in most societies, and it is significantly influenced by values each culture carries (Carrier, 1991; Otnes, Lowrey, \& Kim, 1993). In contrast to some Western societies, the structure of social relations in China rests largely on fluid, personcentered social networks instead of fixed social institutions. Gift-giving therefore plays a significant role in maintaining, reproducing, and modifying interpersonal relations. The Chinese relational construction of personhood represented by the importance of guanxi (personal networks), renqing (personal favor), mianzi (face) and bao (reciprocity) constrains the actions of a gift giver and a gift recipient (Yan, 1996). 
Numerous research on Chinese gift-giving has focused on its instrumental functions such as building business relations or obtaining personal gains (e.g., Chan, Denton, \& Tsang, 2003; Yang, 1994), while some other research has highlighted Chinese gift-giving as a genuine gesture to show goodwill such as appreciation and congratulations (e.g., Joy, 2001; Zhu, Li, \& Qian, 1998). In this study, we focus on the latter. Gift-giving as a genuine gesture to show goodwill is similar to what Malinowski (1978) describes: a desire to please the other motivates gift giving, for which equivalence return considerations are unimportant.

Among other social cultural factors, power and social distance between a gift giver and a gift recipient, value of a gift were found to be related to the presentation and acceptance of a gift in Chinese contexts (e.g., Joy, 2001; Zhu et al., 1998). However, we hardly know to what extent and in what direction these factors influence the ways a gift is presented. In this study, guided by Brown and Levinson's (1987) politeness theory, we explore how Chinese gift-giving is influenced by the three sociological variables central to Brown and Levinson's (B \& L) politeness theory: power, social distance, and ranking of imposition. Through this examination, we seek to achieve two goals: (a) providing information on how the three sociological variables affect gift-giving strategies in Chinese contexts and (b) attesting that B \& L's politeness theory is able to provide theoretical guidance on message production research across cultures albeit recent criticisms on its validity. We employ a repeated measure within subjects design. Participants responded to politeness strategy items in eight Chinese gift-giving scenarios. Analyses centered on the extent to which the three variables influenced positive and negative politeness strategies of Chinese gift-giving. Results revealed significant effects for power, social distance, and ranking of imposition on Chinese gift-giving strategies.

We begin with a discussion of gift-giving as a communicative politeness phenomenon, a review of previous research on Chinese gift-giving, an overview of B \& L's politeness 
theory, critiques, and a discussion of its application in communication research, and then propose how gift-giving can be examined from B \& L's politeness theory perspective.

\section{Gift-giving as a Communicative Politeness Phenomenon}

Gift-giving is primarily a communicative behavior. Presenting and accepting a gift involve sequences of verbal and nonverbal message exchanges. Prior research found giftgiving conversations were sequentially embedded with rounds of message exchanges (e.g., Zhu, Li, \& Qian, 2000). From a communication perspective, in this study, we define giftgiving as verbal and nonverbal communicative behaviors of presenting tangible or intangible objects from one person to another with the intention of expressing good will.

Gift-giving is in Chinese culture also a complicated politeness phenomenon. Its cultural significance is ingrained in the term $l i w u-$ "gift." The Chinese notion of $l i$ was formulated in the time of Confucius $(551 \mathrm{BC}-479 \mathrm{BC})$ and referred to social hierarchy and order in the Zhou Dynasty (dating back to 1100 BC), which Confucius regarded as the model for social and human relations. The ancient books of Liji (Book of Rites), Zhouli (Rites of Zhou Dynasty), and Yili (Book of Etiquette and Ceremonials) together "provided thousands of general principles and guidelines, as well as literally thousands of specific prescriptions, for proper conduct in Chinese society" (Smith, 1983, p. 6). In ancient times, liwu was used as an offer to Heaven or the Emperor. Liwu literally means the material manifestation of $l i$, social order and behavioral norms, so that offering liwu is an important symbolic gesture in interactional rituals. This distinctive meaning has implications for how a gift is presented, since it might be influenced by power and relationship closeness to a greater extent than in other cultures. This line of reasoning shows up in earlier research on Chinese gift-giving.

\section{Chinese Gift-giving Research}

Chinese gift-giving studies have been conducted from a variety of perspectives (e.g., Chan, Denton, \& Tsang, 2003; Joy, 2001; Wang, Razzaque, \& Keng, 2007; Yan, 1996; Yang, 1994; 
Zhu et al., 1998), we review the ones highlighting the influence of power, social distance, and value of a gift on presenting a gift.

Zhu et al. (1998) examined the contexts and functions of gift offering and acceptance, factors affecting the value of gifts and how they were offered and accepted. The authors analyzed 168 questionnaires and found a high solidarity and equal power relationship was more likely to occasion gift offers, and gift-giving was only probable for the medium solidarity of equal power or asymmetrical power relationships. It was also found that the way in which offers were made and responded to by recipients depended on the interpersonal relationship. Specifically, high solidarity, equal power relationships occasioned more use of the straightforward offer-acceptance pattern, while medium solidarity, asymmetrical power relationships occasioned more use of the re-offer-decline exchanges. Further, the authors reported the value of a gift would affect the way the gift was accepted: the more expensive the gift, the more reluctant the recipient would be to accept. Similarly, Joy (2001) found relationship closeness (i.e., close friends, good friends, just friends) influenced gift qualities and presentations in Hong Kong. However, these conclusions were based on qualitative analysis of interviews or self report surveys. Thus, it is not clear whether social relationships, power, and value of a gift would significantly affect how a gift is presented, that is, whether those findings are reflecting a behavioral tendency in a relatively larger population. This could be validated by testing theory-guided hypotheses.

Brown and Levinson's politeness theory entails the three variables of power $(\mathrm{P})$, social distance (D) and ranking of imposition (R), which have been applied in a number of communication studies (e.g., Aronsson \& Rundstrom, 1989; Baxter, 1984; Carson \& Cupach, 2000; Sabee \& Wilson, 2005). We expect that B \& L's politeness theory would provide guidance on studying the social factors influencing Chinese gift-giving messages albeit recent criticism on its validity. It therefore also tests B \& L's politeness theory in a non-Western 
culture in response to the criticism that the theory has an ethnocentric bias: deriving "directly from the high value based on individualism in Western cultures" (Kasper, 1990, p. 252). We argue that B \& L's politeness theory should have implications for communicative behaviors across cultures because the three sociological factors central to the theory are present in many cultures - particularly in Chinese culture in which power and social relationship are much emphasized.

\section{Politeness Theory, Communication, and Gift-Giving}

\section{Brown and Levinson's Politeness Theory, Critiques, and Application in Communication}

"Face" is central to B \& L's politeness theory; to be polite is to save face. A rational human being is assumed to have positive and negative face. Positive face wants involve having one's social image accepted and approved. Negative face has to do with rights to nondistraction and respect for freedom. Politeness theory proposes five strategies in which language is used to save another's face when encountering a "face-threatening act" (FTA). "Bald on record" means that the speaker signals intention in the most clear, direct, and concise way. "Positive politeness" shows concern for the addressee's positive face by treating him or her as an in-group member while "negative politeness" recognizes and respects addressees' wants of freedom of action. By “going off record," hearers get obscure, ambiguous intentions from speakers and "don't do the FTA" simply means saying nothing.

The factors of social distance $(\mathrm{D})$, power $(\mathrm{P})$, and ranking of imposition $(\mathrm{R})$ influence the choice of politeness strategies. Social distance includes closeness and social similarity. Power refers to the degree to which one can impose one's thoughts and plans on another. Ranking of impositions means the absolute level of obligation the speaker wants to communicate to the hearer, often culturally defined. The combination of $\mathrm{P}, \mathrm{D}$, and R affects the "weight" (i.e., degree of face threat) of action in a specific context. When the weight is 
greater, one should choose a more polite strategy; when it is less, a less polite strategy is more appropriate.

After Brown and Levinson published their ground-breaking work on politeness theory in 1978/1987, recent works has raised criticisms and proposed alternative views on politeness theory (e.g., Eelen, 2001; Mills, 2003; Watts, 2003). The major criticism focuses on lacking of consideration of discursive contexts where politeness could be evaluated. That is, whether an utterance is polite or impolite should be evaluated by people who involve in real conversations rather than theoretically defined. This line of research argues for a much more contextually sensitive interpretation of politeness focusing on how lay people engaged in authentic verbal interaction assess utterances as polite or impolite.

Despite these criticisms, B \& L's politeness theory remains influential in interpersonal communication research because the theory highlights speakers' message production - why people say what they do during everyday interaction (Wilson \& Feng, 2007). The theory partly resembles a post-positivistic approach by being able to make predictions about patterns and interpretations of language use (Goldsmith, 2008). In communication research, most commonly, B \& L's politeness theory has been employed to predict communicative behavior. Researchers present participants with situations varying in $\mathrm{P}, \mathrm{D}$, or $\mathrm{R}$, and test to see what politeness strategy they will produce based on those specific scenarios. B \& L's politeness theory is therefore anticipated to provide guidance to the current research: how $\mathrm{P}, \mathrm{D}$, and R influence politeness strategy choices in Chinese gift-giving.

\section{Gift-giving behavior and B \& L's politeness theory}

How can gift-giving be analyzed from the politeness theory perspective? Brown and Levinson argue that an "offer" is an act that threatens a hearer's negative face wants of being free from imposition: The speaker hopes the hearer will commit to whether or not $\mathrm{s} / \mathrm{he}$ wants the speaker to perform some acts. Giving-gift is one kind of offers; by giving a gift, the giver 
may make the recipient incur a debt (Godelier, 1999). Even if the giver simply wants to show appreciation, that still obligates the recipient. Hence, the giver must use appropriate politeness strategies to minimize possible face threats.

Positive and negative politeness strategies appear most relevant to gift-giving situations. During gift-giving, givers may encounter recipients of varying social status and relational closeness. Moreover, a gift may be big or small. Hence, to behave appropriately, gift-givers can consider either positive or negative politeness strategies to reduce face threats. When the weight of an FTA is lighter (close relationship, equal power, small gift), the presenter would likely to use positive politeness strategies; conversely, when an FTA is heavier (distant relationship, higher power, expensive gift), the presenter would likely to use negative politeness strategies.

With respect to power, Chinese culture is hierarchical with differential power distribution among different types of relations. Respect for seniors and superiors have been acknowledged as values in Chinese culture. Relatively high power differences between giver and recipient would lead to an FTA of greater weight, which in turn would make the giver respond more positively to negative politeness strategies. Low power differences between gift-giver and recipient would lead to an FTA of lighter weight, which would make the presenter respond more positively toward positive politeness strategies. Hence,

H1: Power will have a main effect on positive and negative politeness strategies used by a gift-giver. Specifically, a gift-giver will respond more positively toward positive politeness strategies when presenting a gift to a recipient of low power status than to one of high power status (H1a); and a gift-giver will respond more positively toward negative politeness strategies when presenting a gift to a recipient of high power status than to one of low power status (H1b). 
Social distance is also expected to influence choice of politeness strategies. Personal relationships have particular significance in Chinese culture, with closer relationship allowing greater latitude and a strong sense of identification. Positive politeness strategies are likely to be used when a gift-giver and a recipient have a closer relationship, while negative politeness strategies are likely to be used when the two parties have a distant relationship. Hence, hypothesis 2 is generated:

H2: Social distance will have a main effect on positive and negative politeness strategies used by a gift-giver. Specifically, a gift-giver will respond more positively toward positive politeness strategies when presenting a gift to a recipient of close relationship than one of distant relationship (H2a); and a gift-giver will respond more positively toward negative politeness strategies when presenting a gift to a recipient of distant relationship than one of close relationship (H2b).

Ranking of imposition is operationalized as the value of a gift in this study: The more expensive the gift, the higher the imposition. Godelier (1999) points out that gift-giving is a paradox: while the giver reaches out to the receiver through an act of sharing, s/he also places the receiver in a position of indebtedness - accepting an expensive gift normally means incurring greater emotional debt. Hence, giving an expensive gift entails a heavier imposition, which would produce greater negative face threats. In such a situation, one would be more likely to use negative politeness strategies; Conversely, positive politeness strategies would be more likely when a less expensive gift is presented. Accordingly,

H3: Ranking of imposition (i.e., value of a gift) will have a main effect on positive and negative politeness strategies used by a gift-giver. Specifically, a gift-giver will respond more positively toward positive politeness strategies when presenting a gift of low value than a gift of high value (H3a); and a gift- 
giver will respond more positively toward negative politeness strategies when presenting a gift of high value than a gift of low value $(\mathrm{H} 3 b)$.

Beyond main effects for power, social distance, and ranking of imposition, interaction effects will also be examined. However, based on current literature, we do not know how these interactions will affect Chinese gift-giving. Hence, research question 1 is raised: RQ1: What are the interaction effects for power, social distance, and ranking of imposition on positive politeness strategies (RQ1a) and negative politeness strategies (RQ1b) used by Chinese in gift-giving?

\section{Methodology}

\section{Participants}

Participants were $152^{1}$ college students from two large universities in Beijing, China. Participants ranged in age from 18 to 29 years old. The sample comprised approximately $29.6 \%$ males $(N=45)$ and $70.4 \%$ females $(N=107)$. The universities had students from most major cities and provinces of China. As such, participants represented resident Chinese from a variety of geographical areas.

\section{Procedures}

Participants were recruited from classes taught by instructors known to the first author. Participants were informed that their participation was voluntary and students who did not choose to participate were provided with an alternative assignment while their peers filled out the questionnaires. Participants took approximately 25 minutes to complete the survey. 152 valid copies were retained for analysis after copies with missing responses were removed.

\section{Repeated Measure within Subject Design}

This study has three independent variables, each with two levels: power (high vs. low), social distance (close vs. distant), and ranking of imposition (high vs. low). Therefore eight conditions $(2 \times 2 \times 2)$ representing all possible combinations of the three variables were 
created. A repeated measure within subject design is used. This type of design increases power of analysis because all participants respond to questions under each single condition.

\section{Research Instruments}

A questionnaire, in Chinese, was designed to solicit respondents' thoughts on politeness strategies in gift-giving. It had two sections. Section one asked for demographic information. Section two contained (a) eight gift-giving scenarios, each embodying a combination of the three independent variables and (b) six positive politeness strategies and six negative politeness strategies items under each condition. Another questionnaire was designed to evaluate manipulations of power, social distance, and ranking of imposition.

\section{Operationalization of the Three Independent Variables}

The three independent variables were operationalized by considering the literature on B \& L's politeness theory and Chinese cultural assumptions. Power refers to the relative power difference between gift-giver and recipient. In contemporary China, rank, age, and gender are among the basic determinants of power (Pan, 2000). We used seniority in rank (e.g., professor and boss) or generation (e.g., one's aunt, parents, or grandparents) as key sources for power. Social distance concerns whether gift-giver and recipient have a close or distant social relationship. A close relationship was operationalized as one's intimate friend, close family member and relative; a distant relationship was actualized by one's acquaintances at work and school or a friend's parents. As argued earlier, ranking of imposition was operationalized as the value of a gift: the more expensive the gift, the higher the ranking of imposition.

\section{Gift-giving Scenarios}

Eight scenarios were composed reflecting the combinations of power (high vs. low); social distance (distant vs. close); and ranking of imposition (high vs. low). The gift-giving scenarios are based on four occasions with which gift-giving is often associated in Chinese 
contexts: special celebrations (e.g., birthdays); traditional Chinese festivals (e.g., Spring Festival); returning from a long distance trip; and showing thanks for hospitality, kindness, or special service (Zhu et al., 2000). Scenarios 1, 2, 3, and 5 were high power situations, differing from each other by the variables of social distance and ranking of imposition. Scenarios 4, 6, 7, and 8 were low power situations with the variables of social distance and ranking of imposition varying from one level to the other (see Appendix A for details). These scenarios were phrased showing goodwill to recipients, which help us differentiate gift-giving as genuinely expressing goodwill from being an instrumental strategy of building business or personal connections. We asked five Chinese doctoral students to assess realism and clarity of the scenarios. Some wordings were revised based on the feedback. Each scenario was evaluated as realistic.

\section{Manipulation Check for Independent Variables}

To evaluate whether the manipulations of the $2 \times 2 \times 2$ experimental design would work as intended, we designed another survey composed of the eight scenarios with five items under each scenario measured on a 7-point Likert scale. Three items asked respondents to evaluate the value of a gift, power difference and closeness between a gift-giver and a recipient. Two disguising items helped divert the participants' attention from the researchers' manipulation intentions. Thirty Chinese college students in a large university in Beijing China participated in this manipulation check study. Paired-samples $t$-tests revealed that the manipulations were successful: significant differences were found between high power and low power $\left(M_{\mathrm{diff}}=\right.$ $\left.1.87, t_{(1,29)}=9.57, p<.001\right)$, close and distant relationship $\left(M_{\text {diff }}=2.05, t_{(1,29)}=13.95, p<\right.$ $.001)$, and high and low ranking of impositions $\left(M_{\text {diff }}=.76, t_{(1,29)}=4.17, p<.001\right)$.

\section{Measurement Items}

Twelve items (see Appendix B) representing positive and negative politeness strategies were measured on a 7-point Likert-type scale ranging from "strongly disagree" to "strongly agree" 
with 1 standing for "strongly disagree" and 7 "strongly agree." All items were composed according to B \& L's definitions of positive and negative politeness strategies.

Six items were designed as positive politeness strategies. A couple examples will serve to explain our approach. Item 1, "give the gift directly to the recipient when you see him or her," was based on the assumption that the gift-giver does not need to hide his or her intention if he or she treats the recipient as an in-group member. Item 5 was based on the positive politeness strategy, "presuppose, raise, or assert common ground.” By saying " $I$ chose this gift especially for you," the gift-giver presupposes knowledge of the recipient's wants and tastes. The other six items were designed as negative politeness strategies. For example, item 2, "offer the gift at an appropriate moment during casual conversation," was composed according to B \& L's negative politeness strategy, "be conventionally indirect." The gift-giver offers the recipient an "out" by being indirect. Item 4, "when talking with the recipient, you will be polite and respectful," was based on the strategy, "give deference": The speaker does not want to coerce the hearer and wants to leave free space.

We asked three Chinese doctoral students and six undergraduates to read the statements and assess their clarity. Most items were understandable and interpreted as either positive or negative politeness strategies as intended. Some were revised following respondents' suggestions. After data collection, reliability analyses were conducted for positive and negative politeness strategy items under each of the eight scenarios. Alphas for positive politeness strategy items were around .60 while alphas for negative politeness strategies were around .61.

\section{Results}

With a sample of 152 participants and alpha set at $p<.05$, statistical power to detect main effects of power, social distance, and ranking of imposition on the dependent variables was .99 for a small effect size $(d=.20)$ and 1.0 for a medium effect size $(d=.50)$ and large effect 
size $(d=.80)$. Statistical power to detect interaction effects was .89 for a small effect size $(d$ $=.20)$ and 1.0 for a medium effect size $(d=.50)$ and a large effect size $(d=.80)$.

\section{Effect for Power on Gift-giving Politeness Strategies}

H1 focused on the main effect of power and predicted that (a) a gift-giver would respond more strongly toward positive politeness strategies when presenting a gift to a recipient of low power status than to one of high power status (H1a), whereas (b) a gift-giver would respond more strongly toward negative politeness strategies when presenting a gift to a recipient of high power status than one of low power status $(\mathrm{H} 1 \mathrm{~b})$. The hypothesis was evaluated with two $2 \times 2 \times 2$ repeated measures model analysis of variance (ANOVA). The independent variable was power and the dependent variables were, respectively, positive and negative politeness strategies.

Means and standard deviations are in Tables 1 and 2. ANOVA detected a small but significant main effect for power on positive politeness strategies, $F(1,136)=5.89, p<.016$, $\eta^{2}=.04$. The gift-giver was found to respond more strongly toward positive politeness strategies when presenting a gift to a low power recipient $(M=4.68)$ than to a higher power recipient $(M=4.54)$. There was also a significant main effect for power on negative politeness strategies, $F(1,138)=35.32, p<.001, \eta^{2}=.20$. Givers responded more strongly toward negative strategies when presenting a gift to a high power recipient $(M=4.72)$ than to one of low power $(M=4.41)$. Hence, H1 is supported.

\section{Effect for Social Distance on Gift-giving Politeness Strategies}

$\mathrm{H} 2$ focused on the main effect of social distance, predicting that a gift-giver would (a) respond more positively toward positive politeness strategies when presenting a gift to a recipient of close relationship than to one of distant relationship (H2a); and (b) respond more positively toward negative politeness strategies when presenting a gift to a recipient of distant relationship than to a recipient of close relationship (H2b). The hypothesis was evaluated 
with two $2 \times 2 \times 2$ repeated measure model ANOVAs. The independent variable was social distance and the dependent variables were positive politeness strategies and negative politeness strategies.

Means and standard deviations for the analyses are displayed in Tables 1 and 2. The ANOVA revealed a significant main effect for social distance on positive politeness strategies, $F(1,136)=200.24, p<.001, \eta^{2}=.60$. The gift-giver was found to respond more positively toward positive politeness strategies when a recipient was of close relationship ( $M$ $=5.23)$ than to a recipient of distant relationship $(M=3.99)$. The ANOVA also detected a significant main effect for social distance on negative politeness strategies, $F(1,138)=$ $183.16, p<.001, \eta^{2}=.57$. A gift-giver was found to respond more positively toward negative politeness strategies when presenting a gift to a recipient of distant relationship $(M=5.16)$ than to a recipient of close relationship $(M=3.97)$. Therefore, $\mathrm{H} 2$ is supported. We also notice that the effect sizes for social distance on positive politeness strategies and negative politeness strategies are larger than that of power.

\section{Effect for Ranking of Imposition on Gift-giving Politeness Strategies}

H3 examined the main effect of ranking of imposition, predicting that a gift-giver would (a) respond more positively toward positive politeness strategies when giving a gift of low value than a gift of high value (H3a); and (b) respond more positively toward negative politeness strategies when giving a gift of high value than a gift of low value (H2b). This hypothesis was evaluated with two $2 \times 2 \times 2$ repeated measure model ANOVAs. The independent variable was ranking of imposition and the dependent variables were positive and negative politeness strategies.

Means and standard deviations are presented in Tables 1 and 2. ANOVA revealed a significant main effect for ranking of imposition on positive politeness strategies, $F(1,136)$ $=80.48, p<.001, \eta^{2}=.37$. The giver was likely to use positive politeness strategies when 
giving a gift of low value $(M=4.88)$ than a gift of high value $(M=4.34)$. ANOVA also detected a significant main effect for ranking of imposition on negative politeness strategies, $F(1,138)=57.67, p<.001, \eta^{2}=.29$. Givers were likely to use negative politeness strategies when giving a gift of high value $(M=4.75)$ than one of low value $(M=4.37)$. Hence, $\mathrm{H} 3$ is supported. The effect sizes of ranking of imposition on both politeness strategies are greater than of power but smaller than that of social distance.

\section{Interaction Effects}

Research question 1 asked the interaction effects of power, social distance, and ranking of imposition on positive politeness strategies (RQ1a) and negative politeness strategies (RQ1b). Two 2 × 2 × 2 repeated measure model ANOVAs were conducted to answer RQ1.

The first ANOVA detected a small but significant interaction effect for power and distance on positive politeness strategies, $F(1,136)=4.15, p<.05, \eta^{2}=.03$. Decomposition of this two-way interaction effect reveals that the effect for social distance on positive politeness strategies varies as a function of power; specifically, the effect for social distance is slightly weaker $\left(\eta^{2}=.49\right)$ when power is low than when power is high $\left(\eta^{2}=.51\right)$. ANOVA also revealed a significant interaction effect for distance and ranking of imposition on positive politeness strategies, $F(1,136)=8.17, p<.01, \eta^{2}=.06$. As the value of a gift increased (i.e., ranking of imposition), the impact of social distance on positive politeness strategies decreased; specifically, the effect for social distance was greater $\left(\eta^{2}=.56\right)$ when the value of a gift is low than when the value is high $\left(\eta^{2}=.43\right)$. Finally, the ANOVA detected a significant three-way interaction for power, distance, and ranking of imposition on positive politeness strategies, $F(1,136)=52.84, p<.001, \eta^{2}=.28$. This effect is substantially larger than for any of the two-way interaction effects.

The second ANOVA revealed a significant interaction effect for power and distance on negative politeness strategies, $F(1,138)=17.61, p<.001, \eta^{2}=.11$. As power increased, 
the impact of social distance on negative politeness strategies decreased. Specifically, the effect for social distance was greater $\left(\eta^{2}=.51\right)$ when power is low than when power is high $\left(\eta^{2}=.48\right)$. ANOVA also revealed a significant interaction effect for power and ranking of imposition on negative politeness strategies, $F(1,138)=12.47, p=.001, \eta^{2}=.08$. As the value of a gift increased, the impact of power on negative politeness strategies increased significantly. Specifically, the effect for power was small $\left(\eta^{2}=.04\right)$ when value of a gift is low but the effect for power is stronger $\left(\eta^{2}=.28\right)$ when value of a gift is high. The ANOVA also detected a significant interaction effect for distance and ranking of imposition on negative politeness strategies, $F(1,138)=12.12, p=.001, \eta^{2}=.08$. Inspection of the interaction suggested that as the value of a gift increased, the impact of social distance on negative politeness strategies decreased. Specifically, the effect for social distance on negative politeness strategies was bigger $\left(\eta^{2}=.53\right)$ when the gift value is low than that $\left(\eta^{2}=\right.$ .48) when the value is high. Finally, the ANOVA revealed a significant three-way interaction effect for power, distance and ranking of imposition on negative politeness strategies, $F(1$, $138)=72.45, p<.001, \eta^{2}=.34$. This effect is substantially greater than any of the three twoway interaction effects.

\section{Discussion}

The primary purpose of this study was to examine factors influencing the choice of politeness strategies by Chinese when giving gifts. Gift-giving is a social practice and the weighting of the factors is governed by beliefs and practices in Chinese culture.

\section{Power Effects on Politeness Strategies}

Power had significant effects on both positive and negative politeness strategies; however, power exerted stronger influence on negative politeness strategies than on positive strategies. Moreover, among all three variables, power's effects on both types of strategy were the smallest. 
The stronger influence of power on negative politeness strategies can be explained in two ways. First, China is a hierarchical society with power relations much emphasized (The Chinese Connection, 1987). To recognize power relations when communicating with others is considered a primary consideration for behaving appropriately. A deferential style of communication is often in order in the presence of someone of authority (Gao \& TingToomey, 1998). To be deferential, one needs to exercise both restraint and hesitance (Young, 1994). This is similar to B \& L's conception of negative politeness, characterized by selfeffacement, formality, and restraint. The more powerful the recipient, the more respectful the giver is expected to be.

Second, gift-giving is traditionally a respectful behavior in Chinese culture, as demonstrated in the term liwu. Gift-givers tend to use respectful verbal and nonverbal behaviors when presenting gifts to those of high power status. Gifts in asymmetrical relationships were usually offered and accepted discreetly (Zhu et al, 1998). This may also help explain why, in this study, power had greater influence on negative politeness strategies.

Despite B \& L's emphasis on power as one of the most important variables affecting politeness strategies, we found power had the least influence on both politeness strategies. In contemporary China, sources of power are from four factors: rank, gender, connection, and age (Pan, 2000). However, the role of each plays varies according to situation. For example, age usually plays a greater role in family settings while rank counts more in an official setting. One should note that rank traditionally plays a significant role as a power source in China. Among our four high power scenarios, three use generation (seniority in age) as an indicator of power, and only one uses rank. Compared to power represented by rank, the magnitude of power represented by generation in family settings may be small. This may explain why power had the smallest effects compared with social distance and ranking of imposition. Future research should employ multiple balanced power indicators. 


\section{Effects for Social Distance on Politeness Strategies}

Results revealed that social distance had significant influence on positive and negative politeness strategies. Among the three factors, social distance had the strongest effects.

Social relationship is central in China (Chang \& Holt, 1991; Gao, 1998); harmony and solidarity with others are much emphasized. In Chinese culture, social practice seeks to determine type of relation first — entailing different degrees of social distance — and then use politeness strategies accordingly (Pan, 2000). When communicating with those in close relationship, one is expected to express attitudinal warmth $(\mathrm{Gu}, 1990)$ and show similar interests and share feelings which are typical positive politeness strategies. We found that when presenting a gift to someone in close relationship, participants' ratings of positive politeness strategies were well beyond the middle point on a scale of 1 to $7(M=5.23)$.

Gift-givers may feel restrained when giving a gift to one not as close because they need a reason to give, else the act may seem abrupt. In this study, three of four gift-giving occasions in distant relationships were to thank and show appreciation. When thanking someone, one often behaves respectfully, a reflection of negative politeness. This thanking situation could enhance the influence of social distance on the use of negative politeness strategies. Future research may try to avoid this by using multiple balanced gift-giving occasions.

\section{Effect for Ranking of Imposition on Politeness Strategies}

This study found significant effects for ranking of imposition on positive and negative politeness strategies. Among the three factors, the effects of ranking of imposition were in the middle (see effects sizes). In this study, ranking of imposition was defined by a gift's value: the more expensive the gift, the higher the ranking of imposition.

Godelier (1999) pointed out while the giver reaches out to the receiver through an act of sharing, s/he also places the receiver in a position of indebtedness. Accepting an expensive 
gift incurs greater emotional debt which affects negative face wants for freedom from imposition. For example, prior research found a recipient is more reluctant to accept an expensive gift (Zhu et al., 1998). The recipient is expected to decline an expensive gift upon the first or second offer. This cultural value would make the gift-giver equally tactful when presenting an expensive gift. The giver will usually not present a pricey gift directly but offer it at an appropriate moment during conversation, a negative politeness strategy.

From the givers' standpoint, behavioral restraint is necessary to relieve degree of the imposition occasioned by a more expensive gift. These considerations help explain why ranking of imposition had a significant effect on negative politeness strategies.

Similarly, one can infer that the less expensive a gift, the easier the recipient would accept it. The recipient would view this act more as friendly and would not be as likely to think that the giver has ulterior motives. Hence, when presenting a small gift to show goodwill, the giver may often claim common ground with the recipient, to demonstrate shared values or preferences. For example, "I like it very much, and I think you will like it too" is a typical positive politeness strategy. This may explain why ranking of imposition also had a significant impact on positive politeness strategies.

\section{Interaction Effects}

Power and social distance had a small but significant interaction effect $\left(\eta^{2}=.03\right)$ on positive politeness strategies of gift-giving; similarly, social distance and ranking of imposition also had a small but significant interaction effect $\left(\eta^{2}=.06\right)$ on positive politeness strategies. Social distance had a stronger effect on positive politeness strategies when a gift was of low value. As discussed, a less valuable gift possibly incurs lesser emotional debt so that the gift-giver would be less restrained when presenting a gift, particularly someone with whom the giver is close. However, the effect of social distance on positive politeness strategies was smaller $\left(\eta^{2}\right.$ $=.49)$ when power was low compare to when power was high $\left(\eta^{2}=.51\right)$. This is contrary to 
expectations, even though the difference between the effect sizes was slight. Again, this may relate to how power was represented in this study: individuals such as aunt, grandmother, and friends' parents probably were not seen as powerful as high rank officials. And they often are of close relationships which generate positive politeness strategies.

Power and social distance also had an interaction effect on negative politeness strategies. The effect of social distance on negative politeness strategies was smaller when power was high $\left(\eta^{2}=.48\right)$ than when power was low $\left(\eta^{2}=.51\right)$. This is consistent with power's bigger influence on negative politeness strategies. High power led to more positive responses to negative politeness strategies and may have reduced the effect of social distance on negative politeness strategies. Power and ranking of imposition had an interaction effect on negative politeness strategies as well. The effect of power on negative politeness strategies increased significantly when gift value was high. Presenting an expensive gift to someone of high power status required more attention to not imposing on the recipient. Hence, there was higher likelihood of using negative politeness strategies. Further, social distance and ranking of imposition had an interaction effect on negative politeness strategies. The effect of social distance on negative politeness strategies was smaller when gift value was high. As noted, an expensive gift incurs greater emotional debt on the part of the recipient despite relational closeness. The giver would behave with restraint to relieve the imposition occasioned by the more expensive gift. Gift value (i.e., ranking of imposition) then had greater influence on negative politeness strategies.

This study found a much stronger three-way interaction effect than any of the twoway interaction effects, which revealed the complicated nature of Chinese gift-giving as a type of social interaction affected simultaneously by relationship closeness, power, and value of a gift. Future research could explore the details of how they together affect Chinese giftgiving. 


\section{Theoretical and Practical Implications}

The offering of liwu (gift) is an important symbolic gesture in Chinese social interactions. Findings from this study indicate some important underlying mechanisms of Chinese giftgiving: Power difference, relationship closeness, and value of a gift play significant roles in presentation of a gift, which is somewhat consistent with the cultural conceptualization of a gift (liwu) in China. The three factors may influence gift-giving in other cultures as well but the magnitude might be different. Future research may focus on how the three factors affect gift-giving across cultures.

Despite criticisms of B \& L's politeness theory, this study upheld B \& L's politeness theory by revealing significant impact of the three sociological variables on politeness strategies used in Chinese gift-giving. Hence, this study demonstrates that (a) B \& L's politeness theory has its value on predicting gift presenters' communicative behavioral patterns, and (b) B \& L's politeness theory is applicable in a non-Western culture which, to a certain extent, supports B \& L's claim that their theory is universal.

Practically, given increasing personal contacts between China and other countries, this study is useful for communicators in intercultural situations, particularly gift-giving scenarios in the Chinese context. There are abundant anecdotes about foreign visitors being amazed at what they see as a seesaw Chinese battle of gift plying and declining, and bewildered about what to say and do facing a Chinese gift-giving scenario. They could be even more perplexed after reading etiquette books about what one should say when presenting a gift. This study demonstrates that when a small gift is presented to someone close and of equal power, the gift-giver often will present the gift straightforwardly by claiming common ground or looking for similar interests, without being overly careful about the advice in etiquette books. Conversely, when an expensive gift is presented to one of higher power, related more distantly, the giver might consider using respectful verbal and nonverbal messages. 


\section{Limitations and Directions for Future Research}

Several limitations should be noted and addressed in future research. First, measures of positive and negative politeness strategies showed minimally acceptable reliabilities. There are several possible reasons for this level of reliability, including (a) somewhat subjective interpretations and representations of theoretical politeness strategy types in B \& L's

politeness theory; (b) less than ideal operationalization of the independent variable of power; and (c) small number of items used to assess constructs. These shortcomings can be addressed in future research to improve assessment of positive and negative politeness strategies. Low reliabilities can lead to artificially weak effects. More thorough pilot testing of instruments with appropriate samples should lead to enhanced reliabilities.

Second, although design of gift-giving situations was carefully thought out to encompass all variables tested, operationalization of independent variables through scenarios may involve the researchers' subjective selection of appropriate cultural scripts. The extent to which these scenarios accurately capture respondents' views concerning politeness strategies in gift-giving behavior may be limited. There are different situations occasioning gift-giving actions, such as weddings, birthdays, special holidays, as well as occasions for currying favor, showing gratitude, and comforting the sick. In this study, four were used. Among the eight scenarios, three were showing gratitude. Future research needs to address this question by employing multiple balanced gift-giving situations.

Finally, the sample was restricted in terms of age, location, and educational level. Results are primarily generalizable to young, educated, urban Chinese adults, an important, but small, segment of China's roughly 1.3 billion people. Future research would benefit from recruiting a larger sample including respondents of different ages and backgrounds. 


\section{Acknowledgements}

The authors thank Dr. John Green from Purdue University for his valuable ideas on this research and colleagues in China who helped with data collection.

Table 1. Means and Standard Deviations for Rated Positive Politeness Strategies

$(N=152)$

\section{8 conditions}

Low power, low distance, and low ranking of imposition

Low power, low distance, and high ranking of imposition

Low power, high distance, and low ranking of imposition

Low power, high distance, and high ranking of imposition

High power, low distance, and low ranking of imposition

High power, low distance, and high ranking of imposition

High power, high distance, and low ranking of imposition

High power, high distance, and high ranking of imposition
$M$

$\begin{array}{ll}5.43 & 1.29\end{array}$

$\begin{array}{ll}5.28 & 1.39\end{array}$

$4.36 \quad 1.30$

$3.66 \quad 1.35$

$5.71 \quad 1.25$

$4.51 \quad 1.17$

$4.01 \quad 1.26$

$3.93 \quad 1.27$
137

137

137

137

137

137

137

Table 2. Means and Standard Deviations for Rated Negative Politeness Strategies

$(N=152)$

\begin{tabular}{lccc}
\hline \multicolumn{1}{c}{ 8 conditions } & $M$ & $S D$ & $N$ \\
\hline & & & \\
Low power, low distance, and low ranking of imposition & 3.73 & 1.26 & 139 \\
Low power, low distance, and high ranking of imposition & 3.70 & 1.38 & 139 \\
Low power, high distance, and low ranking of imposition & 4.88 & 1.15 & 139 \\
Low power, high distance, and high ranking of imposition & 5.34 & 1.17 & 139 \\
High power, low distance, and low ranking of imposition & 3.67 & 1.35 & 139 \\
High power, low distance, and high ranking of imposition & 4.80 & 1.16 & 139 \\
High power, high distance, and low ranking of imposition & 5.22 & 1.14 & 139 \\
High power, high distance, and high ranking of imposition & 5.18 & 1.14 & 139 \\
\hline
\end{tabular}

\section{Note}

${ }^{1}$ The power analysis module of STATISTICA (Statsoft Inc., 2004) was used to estimate sample size with .90 power to detect a medium-size interaction effect (i.e., $d=0.5$ or $r=.24$; see Cohen, 1988) assuming $\alpha=.05$; no fewer than 63 participants needed to be recruited. Detecting an interaction effect required a larger sample size than detecting a main effect. Hence, we used the sample size of finding an interaction effect as an indicator. We successfully recruited 152 participants, a good sample size for this study.

\section{Notes on contributors}

Hairong Feng (Ph.D., Purdue University, 2007) is Assistant Professor of Communication at the University of Minnesota Duluth. Her research focuses on interpersonal and intercultural communication, with special focus on supportive communication. She has published articles in Health Communication, China Media Research, and others. 
Hui-Ching Chang (Ph.D., University of Illinois at Urbana-Champaign, 1994) is Associate Professor of Communication at the University of Illinois at Chicago. Her research focuses on intercultural communication, especially relationship issues. More recently, she has explored Taiwanese national identity as constituted through various communicative practices. Her publications have appeared in Discourse Studies, Research on Language and Social Interaction, Journal of Language and Social Psychology, Journal of Asian Pacific Communication, and International and Intercultural Communication Annuals.

Richard Holt (Ph.D., University of Illinois at Urbana-Champaign, 1994) is Professor of Communication at Northern Illinois University. His research focuses on organizational communication across cross-cultural boundaries and new media in organizational settings. His published work includes Dialogue on the Internet (Praeger, 2004), and contributions to scholarly journals, including Critical Studies in Mass Communication, Current Anthropology, and Mediation Quarterly.

\section{References}

Aronsson, K., \& Rundstrom, B. (1989). Cats, dogs, and sweets in the clinical negotiation of reality: On politeness and coherence in pediatric discourse. Language and Society, 18, 483-504.

Baxter, L. A. (1984). An investigation of compliance-gaining as politeness. Human Communication Research, 10, 427-456.

Brown, P., \& Levinson, S. (1987). Politeness: Some universal in language use. Cambridge: Cambridge University Press.

Carrier, J. (1991). Gifts in a world of commodities: The ideology of the perfect gift in American society. Social Analysis, 29, 19-37.

Carson, C. L., \& Cupach, W. R. (2000). Facing corrections in the workplace : The influence of perceived face threat on the consequences of managerial episodes. Journal of Applied Communication Research, 28, 215-234.

Chan, A. K. K., Denton, L., \& Tsang, A. S. L. (2003). The art of gift giving in China. Business Horizons, July-August, 47-52.

Chang, H.-c., \& Holt, R. (1991). More than relationship: Chinese interaction and the principle of kuan-hsi. Communication Quarterly, 39, 251-271.

Chinese Culture Connection. (1987). Chinese values and the search for cultural-free dimensions of culture. Journal of Cross Cultural Psychology, 18, 143-64.

Cohen, J. (1988). Statistical power analysis for the behavioral sciences (2nd ed.). Hillsdale, NJ: Laurence Erlbaum.

Eelen, G. (2001). A critique of politeness theories. Manchester: St Jerome.

Gao, G., \& Ting-Toomey, S. (1998). Communicating effectively with the Chinese. Thousand Oaks, CA: Sage.

Gao, G. (1998). An initial analysis of the effects of face and concern for "other" in Chinese interpersonal communication. International Journal of Intercultural Relation, 22, 467-482.

Godelier, M (1999). The enigma of the gift (N, Scott, Trans.). Chicago: University of Chicago Press.

Goldsmith, D. J. (2008). Politeness theory. In L. A. Baxter \& D. O. Braithwaite (Eds.). Engaging theory in interpersonal communication. Los Angeles, CA: Sage. Gould, S. J., \& Wei, C. E. (1991). Gift-giving roles and gender self-concept. Sex Roles, 24, 690-698.

Gu, Y. G. (1990). Politeness phenomena in modern Chinese. Journal of Pragmatics, 14, 237-257.

Joy, A. (2001). Gift giving in Hong Kong and the continuum of social ties. The Journal of Consumer Research, 28, 239-256. 
Kasper, G. (1990). Linguistic politeness : Current resesarch issues. Journal of Pragmatics, 14, 193-218.

Malinowski, B. (1978). Argonauts of the western pacific: An account of native enterprise and adventure in the Archipelagos of Melanesian New Guinea. London: Routledge \& Kegan Paul.

Mills, S. (2003). Gender and politeness. Cambridge: Cambridge University Press.

Otnes, C., Lowrey, T., \& Kim, Y. (1993). Gift selection for 'easy' and 'difficult' recipients: A social roles interpretation. Journal of Consumer Research, 20, 229-244.

Pan, Y. (2000). Politeness in Chinese face-to-face interaction. Stamford, CT: Ablex Publishing Corporation.

Sabee, C. M., \& Wilson, S. R. (2005). Students primary goals, attributions, and facework during conversations about disappointing grades. Communication Education, 54, 185-204.

Smith, R. J. (1983). China's cultural heritage. Boulder, CO: Westview.

Statsoft (2004). Statistica: The small book. Tulsa, OK: Microsoft Corporation.

Wang, Q., Razzaque, M. A., \& Keng, K. A. (2007). Chinese cultural values and giftgiving behavior. Journal of Consumer Marketing, 24, 214-228.

Watts, J. R. (2003). Politeness. Cambridge: Cambridge University Press.

Wilson, S. R., \& Feng, H. (2007). Interaction goals and message production: Conceptual and methodological developments. In D. Roskos-Ewoldsen \& J. Monahan (Eds.), Communication and social cognition (pp. 71-95), Mahwah, NJ: Erlbaum.

Yan, Y. (1996). The flow of gifts: Reciprocity and social networks in a Chinese village. Stanford, CA: Stanford University Press.

Yang, M. M.-h. (1994). Gifts, favors and banquets: The art of social relationships in China. Ithaca, NY: Cornell University Press.

Young, L. W. L. (1994). Crosstalk and culture in Sino-American communication. Cambridge University Press.

Zhu, H., Li, W., \& Qian, Y. (1998). Gift offer and acceptance in Chinese: Contexts and functions. Journal of Asian Pacific Communication, 8, 87-101.

Zhu, H., Li, W., \& Qian, Y. (2000). The sequential organization of gift offering and acceptance in Chinese. Journal of Pragmatics, 32, 81-103. 


\section{Appendix A. Eight Gift-giving Scenarios}

Scenario 1: You have a good relationship with your aunt (much older than you) who lives in the city where you go to university. She gave you significant assistance (e.g., inviting you for dinner, buying you clothes, and giving you money to assist your learning). After graduating from the university and finding a job, you wanted to give your aunt a big gift to thank her for her hospitality and kindness.

Scenario 2: Your best friend's parents came from another city. They invited you to dinner together with their family. When they left for home, you prepared them a small gift to return their hospitality even though you did not really know them very well.

Scenario 3: Professor Lin is an expert in statistics in your department. You are writing a paper related to statistics. While constructing the paper, you came across a big question in statistics. You do not have a close relationship with him, but have only talked to him twice. You have no others to turn for help other than Professor Lin. Professor Lin was kind and spent lots of time on your paper and helps you out at last. You make great progress on your paper. You want to thank Professor Lin by sending him a well-selected gift.

Scenario 4: One of your intimate friends, Wang, is going to another country to develop his career. It will be difficult to see him after separation. Before he leaves, you prepare him a carefully selected gift.

Scenario 5: Your grandma has a close relationship with you. You brought her a small souvenir when you returned from a long-distance trip.

Scenario 6: During Spring Festival, your best friend Chen Chen invites you to have a dinner at her home. When you go to her home, you bring her a small gift.

Scenario 7: Your boss has assigned you the job of drafting a contract for a big business partner. Whether it is successful or not will affect your promotion. One of your acquaintances, Wu Dong, is very experienced in writing business contracts. Though you are not very familiar with him, you asked him for help. He gave you valuable suggestions and finally makes the contract a success. To thank him for his help, you visited him during Spring Festival and gave him a gift.

Scenario 8: Zhou Yun is your classmate, and you only have a so-so relationship with him. Once, he invited you to his birthday party. You bought a gift for him to celebrate his birthday. But you could not attend the party because of time conflict. You then went to his place earlier and gave the birthday present to him. 


\section{Appendix B. Politeness Strategy Items}

1. Give the gift directly to the recipient when you see him/her.

2. Offer the gift at an appropriate moment during casual conversation.

3. When talking to the recipient, you use intimate language.

4. When talking to the recipient, you will be very polite and respectful.

5. Say: "I chose this gift especially for you."

6. Tell that person you like the gift.

7. Say you do not know whether s/he likes the gift or not.

8. Say you think s/he must like the gift.

9. Give good reasons for offering the gift.

10. Say: "this is only a small gift to show my gratitude."

11. Your manner is proper and restrained.

12. Describe in detail how you bought the gift. 